\title{
Free online search days and interlibrary loan
}

\author{
By Sallie H. Barringer
}

Science Librarian

Trinity University

\author{
and Paul Frisch
}

Head of Reference

Southwest Missouri State University
In libraries and other complex organizations, an upgrading of service in terms of quantity or sophistication frequently has an impact on areas beyond the initiating unit. Intelligent library planning requires the anticipation of increased demands on library resources which may arise from introducing a new public service, or promoting or improving an existing service. Access to online and CD-ROM databases, in particular, are public services which may have significant impacts upon reference, circulation, acquisitions, and interlibrary loan.

Since some citations found through online and CD-ROM database searches may not be owned by a library, it is reasonable to expect a rise in the number of interlibrary loan requests when these services are used more than usual. There are several studies on the connection between online database searching and interlibrary loan, mainly from medical, scientific, and technical libraries, all with large clienteles of frequent users of online searching. ${ }^{1}$ No studies were found which examine this relationship in college or university libraries. These libraries generally conduct fewer online searches than special libraries, often because user charges discourage students and faculty from taking advantage of the service. As more academic libraries consider end-user searching through lower-cost, after-hours online databases and subscriptions to CD-ROM databases, it is important that librarians understand what impact access to these formats is likely to have upon requests for interlibrary loan borrowing.

Trinity University is a primarily undergraduate institution with a student body numbering around 2,500 and a faculty of 225 . The reference librarians had become concerned that students and teaching faculty were unaware of the possibilities of computerized information sources and wanted to publicize these services. They had been doing online searching on a cost-recovery basis since 1981, but

${ }^{1}$ Jean K. Martin, “Computer-Based Literature Searching: Impact on Interlibrary Loan Service," Special Libraries 69 (January 1978): 1-6; Mary L. Calkins, "Online Services and Operational Costs," Special Libraries 68 (January 1977): 13-17; and Donald T. Hawkins, "Impact of Online Systems on a Literature Searching Service," Special Libraries 87 (December 1976): 559-67. the number of searches had remained low, averaging between 200 and 250 per year. They had also begun to introduce online searching as a part of bibliographic instruction for upper-level classes, especially in the sciences; however, they wanted to do something that would allow a large number of students and faculty to take advantage of the service at a minimal cost. It was decided to experiment with setting aside a day for free online searching for students and faculty, using a special eight-hour password from BRS Information Technologies.

This free search day was planned for October 1 , 1987. While we encouraged students and faculty to come in and plan searches with librarians in advance, we did not require it. We did 83 searches, for 74 students and 9 faculty. Users entered the search room, where they were met by a librarian who helped them plan a search strategy, had their search done by another librarian, and filled out an exit survey. While some search requests were accepted in advance, and performed in absentia, the majority of the searches were done on a first-come, first-served basis with the user present. There was no attempt at a follow up interview or extensive assistance, although the students were directed to the reference desk if they had any problems; the reference staff spent considerable time explaining how to find the articles that had been retrieved.

The effect of the free searches on interlibrary loan (ILL) was immediate. Around 80 requests were submitted on October 1 , the free search day itself, mainly from users of the free search day. This was considerably more than the $20-30$ requests submitted on a typical day. The interlibrary loan operation had seen a great increase in requests over the past year; the free search day only increased this trend through the fall. There was some concern about the effects of the free search day on a service that was already working hard to provide timely service. It was decided to track the effects of the free online searches on ILL through the entire semester. Lists of students and faculty who had had searches done were compared with the ILL requests filled during this period. During October 1987 , interlibrary loan requests increased by $63.4 \%$, up 106 from the same period in 1988 . During November, requests increased by $9 \%$, and in 
December requests increased by $8.8 \%$. Overall, during the October-December period of 1987 , book ILL requests went up $25 \%$, from 243 to 304 , and journal article requests went up $31 \%$, from 271 to 354 . Those students and faculty who had searches done represented 158 , or $24 \%$, of the total of these requests, more than accounting for the increase. Of these, 133 were submitted in October.

Because of the positive public response to the first free online search day, two more such days were held during the following semester, Spring 1988. Searches for students were done on February 25 and the morning of March 3; faculty searches were done on the afternoon of March 3. A total of 98 searches was done over the two days -87 for students and 11 for faculty. In contrast to the first free search day, students and faculty were each required to meet with a librarian in advance to plan their search strategy, and had to set a definite time to have their searches done. By setting a schedule for individual searches, we hoped to relieve the congestion in the search room and the strain on the librarians that resulted from the drop-in service of the October free search day and to improve the users' understanding of the service. Also, following the search, each person was required to meet with a librarian to discuss how to interpret their printout, and how to find the various materials listed. Interlibrary loan was specifically mentioned as a possible method of obtaining necessary books or articles. ${ }^{2}$

As before, there was an immediate effect on interlibrary loan. The impact of the free searches was apparent in February: 191 ILL requests during February 1987, as compared with 251 in February 1988, an increase of $31.4 \%$. During March, the difference from the previous year was more dramatic, paralleling the increase in October 1987. During March 1987, 221 ILL requests were made. During March 1988, 349 requests were made, an increase of $57.9 \%$. During April 1988, there were 200 requests, actually a $12 \%$ decline from 228 requests during April 1987. The bulk of the 102 ILL requests attributable to the free search days were submitted in between February 25 and the end of March. This represented $12.7 \%$ of the total number of requests filled during the three month period; however, since all but 11 of these requests were submitted between February 25 and March 18 , the actual impact on the interlibrary loan operation was much more concentrated.

The 102 requests resulting from the two Spring free search days actually represented a $64.5 \%$ decrease from the 158 requests from the free search

${ }^{2}$ For suggestions on educating users concerning their online search printouts, see Bruce Connolly and Cheryl M. LaGuardia, "The Impact of Database Searching on Interlibrary Loan: 'Eliminating the negative," Online Review 10 (June 1988): 185-89. day the previous Fall. While there is no data to indicate any correlation, one possible reason for the decline is that students' consultation with a reference librarian may have helped them choose the most appropriate citations on their printout, instead randomly requesting them through ILL. ${ }^{3}$

In summary, our experience has demonstrated that when a library begins a new service-whether it be CD-ROM databases, subsidized end-user searching, or free online searching-that gives library users quick access to a large body of information that is not found in their library, there will be a discernible effect on interlibrary loan requests. Furthermore, if the library actively promotes alternative ways to obtain materials not owned by the library, such as ILL, the effect will be even more pronounced. Thus, any library planning to begin one of these services should carefully consider how other service areas of the institution will be able to meet increased demand.

${ }^{3}$ Ibid., 188.

\section{Conference on forged documents}

The recent discovery of alleged forgeries among early Texas printed documents is a matter of serious concern. The University of Houston Libraries are pursuing an active role in assisting further investigations, according to library director Robin N. Downes.

Austin printer and rare book dealer $W$. Thomas Taylor has questioned the authenticity of certain copies of thirteen printed documents relating to the history of Texas. Taylor has identified printing irregularities in copies whose provenance cannot be established before 1972 . These suspected forgeries are owned by thirteen institutions and a number of private collectors. Pat Bozeman, head of special collections, has stated that four such documents are owned by the University of Houston (numbers 7, 165, 1082 , and 112.1 , as listed in Thomas W. Streeter's Bibliography of Texas, 1795-1845).

Issues relating to forged documents will be the focus of a conference sponsored by the University of Houston. Topics will include forgery detection, scholarly considerations, institutional responsibilities, tax and legal implications, and dealer/donor/institutional relations. This two-day conference will be held in late $\mathrm{Oc}$ tober 1989. For further information, contact Pat Bozeman, Head of Special Collections, University of Houston Libraries, Houston, TX 77204-2091. 


\section{ACQUISITION PERSPECTIVES}

3. We provide each customer a listing of books not immediately available from the publisher. This monthly open order report assures you we have recently taken effective action towards earliest possible delivery of your orders. Publisher stock status and additional information are available on a continuous computer printout or on individual $3 \times 5$ slips for easy filing. We cancel only publisher-documented out-of-print or out-of-stock-indefinitely titles.

Eliminate your claiming and begin receiving your open order reports from Book House.

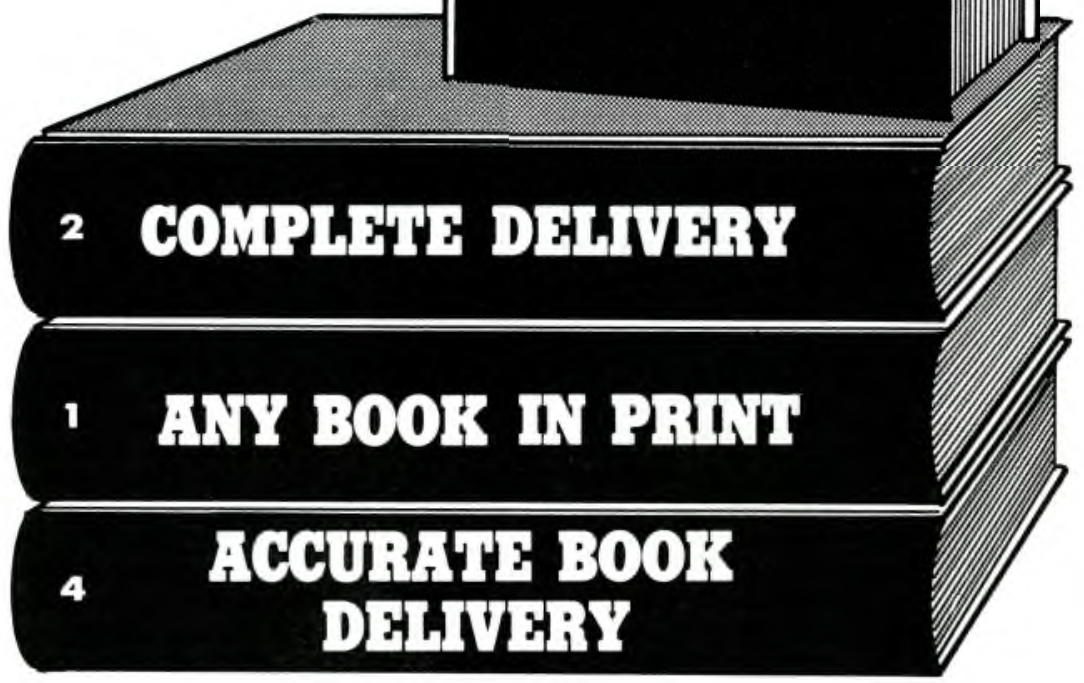

CALL TOLL-FREE TODAY

1-800-248-1146

In Canada \& Michigan

CALL COLLECT (517) 849-2117

OCLC Vendor No. 17397

SAN $169-3859$ the

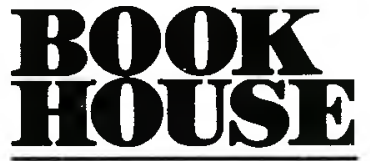

JOBBEAS SERVING LIBAARIES WITH ANY BOOK IN PRINT SINCE 1962 208 WEST CHICAGO STREET JONESVILLE, MICHIGAN 49250 